\title{
The role of technology in fostering creativity in the teaching and learning of mathematics
}

\author{
Balarabe Yushau ${ }^{a}$, Andile Mjib and Dirk C. J. Wessels ${ }^{b}$ \\ King Fahd University of Petroleum \& Minerals ${ }^{a}$, and University of South Africa ${ }^{b}$ \\ Email: byushau@kfupm.edu.sa, mjia@tut.ac.za, and wessedcj@unisa.ac.za
}

\begin{abstract}
The paper looks at interrelationships between creativity and technology in the teaching and learning of mathematics. It suggests that a proper use of various technologies especially computers in the teaching and learning of mathematics has the potential of helping learners to develop their creativity. The technologies can provide an atmosphere under which mathematical skills can be extended beyond the ability to calculate or reproduce problems and enable learners to investigate, analyse and interpret problems at hand. Furthermore, with computers learners can use an experimental approach to deal with mathematical problems, which can lead to conjecture, pattern finding, examples and counter examples. In fact, if used effectively, computational aids can help in improving learners' intellectual ability and hence mathematical achievement while fostering the requisite creativity not found in the traditional approach.
\end{abstract}

\section{Introduction}

Anyone who presumes to describe the roles of technology in mathematics education faces challenges akin to describing a newly active volcano - the mathematical mountain is changing before our eyes, with myriad forces operating on it and within it simultaneously (Kaput 1992: 515).

Despite their side effects, technological advancements have produced a multitude of machines and gadgets with fascinating functions, features, and options. Such machinery and gadgetry are aimed at changing human lives and improving our varied endeavours. The impact of these technological innovations is glaring. In communication terms, the world is now a global village, where the internet, satellites, and mobile telephones are commonly used. The latter years of the past century have brought a vast improvement and unprecedented growth in information dissemination. Transportation has been vastly improved, now it takes a few hours to travel thousands of kilometres. Similar improvements have taken place in the health and educational sectors. Education is one sector that has most benefited from current technological advancement. With this development, time and space are no longer barriers to education. As a matter of fact, the concept of distance learning has been revolutionised to what is now known as e-learning, blended learning or web-based learning programs. In what is now popularly known as distributed learning, people use a wide range of computing and communications technology to provide learning opportunities beyond the time and place constraints of the traditional classroom.
However, the real impact of technological advancement is not the superficial, glitzy or flashy attributes of these machines. The true transformation technology has brought is in its support of the human day-to-day activities. All this has had an impact on real human cognition. It has affected the way we think and in some respects altered the way we think.

It should be remembered that all advancements are a product of human creativity. This has led to arguments about what accelerates what. Is it human creative thinking that generates technological advancement or is it the other way round? Perhaps more pertinently, how do people think and engineer these technological breakthroughs? How is their thinking different from others? What are the factors that trigger this kind of creative thinking? What are the roles of nature and nurture in creative thinking? How can we promote this kind of "special" thinking in our classrooms in general and in the mathematics classroom in particular?

In this paper we examine the interrelationship between creativity and technology in the teaching and learning of mathematics. It is argued that technology, especially computer technology, has the potential for creating a conducive environment and an atmosphere that can engage learners in genuine mathematical activities that can foster creativity. Furthermore, these technologies can equip teachers with the necessary tools for creative teaching that can assist in promoting creativity in their learners. To buttress these points, this paper is divided into seven subsections. After the introduction, the second section briefly discusses 
educational technology. The third section deals with creativity in the teaching and learning of mathematics, while the fourth section gives four areas in which creativity can be promoted in the mathematics classroom. The fifth section discusses the role of technology in developing a quasiempirical view of mathematics. The sixth section reflects on the potential of technology in fostering creativity in the teaching and learning of mathematics. The last section offers a concluding remark.

\section{Educational technology}

The website www.dictionary.com defines technology as:

- The application of science, especially to industrial or commercial objectives.

- The scientific method and material used to achieve a commercial or industrial objective.

Based on this, educational technology can be defined in two ways. First, it has to do with the instruments used in classrooms for the achievement of educational objectives. Second, it concerns the methodology and materials used in the application of instructional principles for the achievement of educational objectives. From these definitions, educational technology encompasses many everyday and familiar objects that may be taken for granted in the teaching and learning context. Examples of these are books, blackboards, charts, maps and models. In fact, it has been argued that rewarding a child with a smile and saying well done when the child performs an act that conforms to the teacher's intention is employing educational technology (Heimer, 1972). The argument is that the teacher acts as an instructional tool to carry out techniques designed to achieve the teacher's goal for the child's behaviour. Implicit in the above definitions are media borne communication and instructional materials such as films, filmstrips, slides, television, calculators, computers, etc. (Heimer, 1972; Carnegie Commission, 1972). The computer and the internet/web have revolutionised the world of educational technology because they have fully integrated the features of other media for easier and more user friendly instructional use. The dominance of the computer is in fact so apparent that instructional aids can now be categorised as computer-related and non computer-related material.

Educational technology has made available different training methods that have hitherto been difficult for human instructors to use. As a matter of fact, the introduction of technology into the educational system has been considered a major revolution in education (see Carnegie Commission, 1972). In particular, the role of technology in mathematics education is so tremendous that it is difficult to describe, while the changes are so rapid that they are difficult to follow (Kaput, 1992). However, both advocates and sceptics of technology are keenly interested in what mathematics education research has to say about it in the teaching and learning of the subject (Cangelosi, 1996). As Papert (1990) rightly notes, "technology is not the cause of anything either positive or negative, but rather should be thought of as a tool that society can use to shape the environment" (in Edwards, 2001: 221). However, the real challenge is how to best utilise these technologies to achieve our educational objectives. In other words, how can we use technology to serve as a catalyst for positive change and as an accompaniment to the teaching and learning situation? In this case, technology should be used for "enrichment and improvement of the conditions in which human beings learn and teach" (Carnegie Commission, 1972: 89), and not as an end in itself. When used in this sense, research has shown that the benefits of using technology such as computers, graphing calculators, etc. are immeasurable and incomparable to traditional teaching approaches (see Carnegie Commission, 1972; Dunham \& Dick, 1994; Roblyer, 1989; Kadiyala \& Crynes, 1998; Corcoran, 2000; Krska, 2001; Setzer, 2001).

\section{Creativity in the teaching and learning of mathematics}

The creative act is often portrayed as

a mysterious and even mystical process, more akin to divine inspiration than to mundane thought... However, with the advent of contemporary cognitive science, psychology has come much closer to appreciating the mental processes that must participate in the creative act. (Simonton, 2000: 152)

Creativity is a complex phenomenon that is difficult to define (Standler, 1998; Meissner, 2000: 151). Consequently, many experts from different disciplines have resorted to a descriptive approach. Simonton (2000) describes creativity as "one of the special ways that human beings display optimal functionality." Quigley (1998: 1) simply puts it as "...the ability to produce something effective and novel." While Standler (1998) resorts to giving the difference between creativity and intelligence vis- 
$\grave{a}$-vis the creative person and the intelligent person. According to him intelligence is the ability to learn and to think, while a creative person does things that have never been done before. A tacit implication in this definition is that most creative people are intelligent but the converse is not always the case.

It has been argued (Jacob, 1996; De Villiers, 2004) that creativity can be categorised into two distinct types, (1) flash out of the blue and (2) process of incremental revisions. In 'flash out of the blue', creativity arrives in a sudden warm embrace, leaving one with a giddy sense of inspiration, vision, and purpose which results in a moment of clarity that is both inexplicable and undeniable (Jacob, 1996). In the 'process of incremental revisions,' creativity is hard work, where one starts with a vague creative seed and spends countless hours of revision and rethinking to hammer out a work through blood, sweat, and tears, but mostly through frustration (Jacob, 1996). Four points have been cited by Ripple (1989, in Edwards, 2001: 222) as the basic assumptions that underlie our understanding of creativity: (a) it is a conceptually identifiable phenomenon, (b) it can be measured, (c) it has distinctive characteristics and developmental patterns, and (d) its development can be facilitated through education and training programmes (Edwards, 2001: 222). Using these assumptions, research has progressed in the area of creativity in four directional fronts: (1) the cognitive process involved in the creative act, (2) the distinctive characteristics of the creative person, (3) the development and manifestation of creativity across an individual lifespan and (4) the social environments most strongly associated with creative activity (Simonton, 2000).

Researchers have reported that creative people possess some special qualities that perhaps help them in their unique way of thinking. In particular, Schmalz (1988) has identified four key individualities that are common among the most creative mathematicians. These are: sustained attention, commitment, detachment from results, and growth in inner confidence. Other researchers have pointed out that creative personalities are usually restless, rebellious, courageous, diligent, arrogant, and independent (Cangelosi, 1996; Meissner, 2000). They have a willingness to take risks, overcome obstacles, tolerate ambiguity, do not like to go in a conventional way, have a desire to shake things up, and are dissatisfied with the status quo (Sriraman, 2004). Creative people tend to prefer situations with a high degree of disorder and irregularity, as they derive their joy by regularising and organising ambiguous things into a unified and meaningful whole. Their thinking mode tends more toward introversion and intuition (Edwards, 2001).

Cangelosi (1996) has reported that in the mathematics classroom, mathematics creativity is displayed by learners who think divergently. These are learners who generate ideas, conjectures, algorithms, or problem solutions. He describes divergent thinking as atypical reasoning that is different from the 'normal' way of thinking. It occurs in situations where 'unanticipated and unusual' responses are anticipated and accepted. In a study conducted in South Africa, Nakin (2003) for example, reported a link between creativity, divergent thinking and effectively learning geometry. All these point to the fact that motivation, engagement, imagination, relative freedom, independence of thinking, relative originality and flexible thinking are necessary for fostering creative thinking (Cangelosi, 1996; Meissner, 2000).

However, an alarming fact for educators is the rate at which the enthusiasm of young children for mathematics disappears step by step as they grow older (Freudenthal, 1973; Meissner, 2000). Some concerned educators are even asking the question: Do people's mathematical intuitions and skills increase or decrease with school knowledge? (Noddings, 1994: 99). It is known that children are generally highly creative, with vivid imaginations; they learn by exploring, risking, manipulating, testing, and modifying ideas until they reach school going age (Paul \& Kathy, 1990). As they enter school, their divergent thinking gradually changes to its antithesis - convergent thinking. Convergent thinking is reasoning that produces predictable responses for most people (Cangelosi, 1996). This type of thinking results in a steady decline in curiosity and creative activity during the school years. In a study, Westby and Dawson (1995) examined elementary school teachers' impact on learner creativity and found that teachers' ratings of their favourite learners were negatively correlated with creativity. The findings indicated that teachers' perceptions of learners as creative were only a positive trait as long as the learners were also easy to manage. Therefore, learner creativity was only fostered to the degree that learners could learn to channel their creativity into acceptable behaviours. If not, teachers were more likely to extinguish creative behaviour than encourage it (Edwards, 2001: 222). 
It appears therefore that, in order to enhance creative thinking, a necessary condition is the openness to new ideas and the willingness to encourage the exploration of the unknown. And hence, there is a need for more curious learners who dare to ask why rather than a docile lot who always say: Yes I understand. Teaching approaches that project mathematics as a rule-based subject are not conducive to creative thinking. Typically, learners' curiosity is stifled in such instances and the most creative minds are discouraged. For more creative learners such classrooms are 'torture zones' because they cannot express themselves. It should be remembered that creative people are unique in their ability to achieve anything. This means that they hardly function optimally under restricted conditions or when things have to be done in accordance with confining rules. It can therefore be argued that creativity is incompatible with mathematics teaching that does not allow learners 'free expression'.

\section{Promoting creativity in a mathematics classroom}

Many studies have attempted to unveil how creative mathematicians create their mathematics. A more recent study is by Sriraman (2004). As a result, many models and theories have been developed. For a more elaborate review on the new trends, perspectives and theories of creativity, see Sriraman (2004). It has been argued that to promote creativity in our classrooms, Polya's vision of trying to make learners do mathematics following a heuristic approach akin to professional mathematicians has been considered as outstanding (Sriraman, 2004). Many researchers have suggested ways that teachers can nurture creativity in their learners (Chambers, 1972; Paul \& Kathy, 1990; Cangelosi, 1996; Meissner, 2000; Sriraman, 2004). We shall summarise and synthesise these in the following four points.

\section{Relative freedom and independence}

A necessary requisite for divergent thinking is relative freedom and independence. To develop this thinking, mathematics teachers should learn to relax the rigidity of following only one way of doing mathematics. They should respect the unusual questions learners ask, and their unusual ideas and solutions, for children will see many relationships that their parents and teachers miss. Teachers should encourage this exploration and provide opportunities and an atmosphere for free expression. They should also give credit for selfinitiated learning. The classroom atmosphere should promote divergent thinking. Overly detailed supervision, too much reliance on prescribed curricula, failure to appraise learning resulting from a learner's own initiative, and attempts to cover too much material with no opportunity for reflection interfere seriously with such efforts (Paul \& Kathy, 1990). Learners should be given more freedom to do their work, and they should be made to believe that it is really their work not the teacher's.

\section{Challenging problems}

The literature suggests that most creative individuals tend to be attracted to complexity, of which most school mathematics curricula has very little to offer. Classroom practices and math curricula rarely use problems with the sort of underlying mathematical structure that would necessitate students' having a prolonged period of engagement and the independence to formulate solutions. (Sriraman, 2004: 32)

Children's potential to solve problems in unprecedented ways is enormous. It has been shown that even children who seem to be mathematically weaker or slower than others can construct powerful mathematical concepts and generalisations provided the tasks they are presented with remain challenging and are not made easier, and the inquiring nature of the mathematics classroom is maintained (Murray, Olivier \& Human, 1992). However, teachers have to provide opportunities for creative expression, creative problem solving and constructive response to change. We need challenging problems to trigger creative thinking and so challenge the learners' potential. Challenging problems are stimulating for learners. However, they can be boring if there is no interest in the contents or if they are too demanding. Therefore, the problems must be connected with the individual daily life experiences of the learners. We must meet their fields of experiences and their interest areas. The learners must be able to identify themselves with the problems and their possible solutions. The problems must be fascinating, interesting, exciting, thrilling, important, and thought provoking (Meissner, 2000).

\section{Encouraging/facilitating learners' efforts}

As learners are faced with challenging problems, there is need for the teachers to guide them towards the solution without too much interference. Learners should be guided and 
encouraged, otherwise, they can get frustrated and discouraged. In a study conducted by Chambers (1972), it was found that individual encouragement was the best teacher behaviour to develop creativity in the learner (in Edwards 2001: 222). Teachers should encourage curiosity, exploration, experimentation, fantasy, questioning, testing, and the development of creative talents. At the same time they should provide adequate guidance and avenues for learners to develop important abilities to explore and visualise a problem, to invent their own or to modify given techniques, to listen and argue, to define goals and to cooperate in teams. Learners should be prepared for new experiences, and helped to develop creative ways of coping with them. Teachers should create an environment that will first further individual and social components of creativity, like motivation, curiosity, selfconfidence, flexibility, engagement, humour, imagination, happiness, acceptance of self and others, satisfaction and success. Learners should be taught to appreciate and be pleased with their own creative efforts.

Furthermore, learners should be exposed to examples of creative production (for instance through historical accounts of mathematical inventions and discoveries, teachers can model divergent thinking in their learners). Similarly, heuristic activities such as brainstorming and openended question sessions should be facilitated. In addition, discussions in which ideas for consideration are examined regarding purpose, structure, advantage, and disadvantages should be encouraged (see Polya, 1957).

Teachers should be aware of the natural curiosity of their learners, and they should be encouraged to discover their environment. They themselves must describe and order or classify their observations, their activities, their questions, and their results. The teacher is only the guide through the "mathematics jungle". Teachers must meet learners' fields of interest and interweave these fields with relevant mathematical content. As teachers, we must guide the intuitive, unconscious, global, spontaneous and visual approaches smoothly into teamwork discussions to further arguing and local logical thinking. On this path, guess and test procedures are not only allowed, they are necessary intermediate steps to gain a more conscious and systematic overview for the given problem (see Polya, 1957). The aim is to show learners that their ideas have value by listening to their ideas, and encouraging them to test them and communicate them to others.

\section{Enough time for brainstorming, exploration and experimentation}

Creative individuals are described as having a greater degree of personal openness, an internal locus of self-evaluation and the ability to toy with materials for considerable lengths of time (Edwards, 2001, Sririman, 2004). Therefore, when learners are faced with challenging problems enough time and opportunity should be provided for them to learn, think, and discover without threats of immediate evaluation. Constant evaluation, especially during practice and initial learning, discourages learners from using creative ways to learn. We must accept their honest errors as part of the creative and learning process.

South Africa has the potential to put the above proposal into practice. An example is the learning situation described by De Villiers (2004), which is supported and integrated with a subject-typified computer-based program, such as Geometer's Sketchpad. This type of dynamic learning environment provides a basis for effective learning and the accompanying thrust for creativity and divergent thinking.

\section{The role of technology in developing a quasi-empirical view in mathematics}

The importance of technology in mathematics and mathematics education is examined in De Villiers' (2003 and 2004) articles on quasi-empirical methods in this area. He argues that technology (in this case the computer) with the dynamic mathematics programs (Geometer's Sketchpad) is an immensely powerful tool that could be used to 'attack' and 'shake' an epistemological perspective, like a one-eyed axiomatic-deductive view about geometry. He convincingly shows that the opportunity to do investigations, explorations and the formulating of conjectures is much wider. Taking experimentation and quasi-empirical methods as synonyms (2004: 2), he elaborates on the different functions of quasi-empirical methods which are: conjecturing, verification, global refutation, heuristic refutation, and understanding. When these functions are active, the participant's intuition is activated. This plays a leading role in one's struggles with problem solving experiences in geometry and mathematics in general. In explaining this De Villiers (2004: 4) cites Hofstadler in relation to mathematical modelling, who points out:

Probably the main reason these ideas are only now being discovered is that the style of exploration is entirely modern; it is a kind of experimental mathematics, in 
which the digital computer plays the role of Magellan's ship, the astronomer's telescope, and the physicist's accelerator. .... And perhaps after it (this era) we will witness a flurry of theoretical work to back up these experimental discoveries.

De Villiers adds: “... the main advantage of computer exploration of topics ... is that it provides powerful visual images and intuitions that can contribute to a person's growing mathematical understanding ..." (2004: 5). With such technology one may be tempted to draw the conclusion that the 'gap' (if any) between experimentation and creativity in mathematics is very small. Using himself as an example, De Villiers (2004) has often described his own experiences of working in this mode and struggling to 'see' the solution. He has shown how working consistently has enabled him to make breakthroughs and to prove conjectures. He was successful because he focused on solving the problem and used all the problem solving strategies in his armoury. Dealing in this way and at this level with problem solving strategies made him creative. Without the use of the computer and Geometer's Sketchpad, it is rarely possible to reach this level of constructive engagement and to solve problems creatively. For De Villiers the ideal situation is when quasiempirical methods and deductive methods complement each other in everyday research mathematics. Both are constituent and very necessary for the 'making' of new mathematics. With the help and mediating role of dynamic mathematics, creativity will flourish in such an environment.

Several conclusions can be derived from De Villiers' retrospection and metacognition. The most important is the natural display of the four attributes of highly creative personalities in mathematics: sustained attention, commitment, detachment, and inner growth of confidence as identified by Schmalz (1988).

In our last experiment (Yushau, Mji, Bokhari \& Wessels, 2005) using MATLAB to teach trigonometric functions, all the four qualities were vividly observed in many learners. Spending considerable time working in the lab with a high level of attentiveness, experimenting with many things, generating different types of graphs of a "strange" function that they could not have dreamt of prior to that experience, they could see the effect of changing parameters, the meaning of "translation", "reflection", "identity", and various forms of symmetry, etc. As the learners visualised these concepts, their confidence increased.

\section{Creativity and technology in the teaching and learning of mathematics}

Several researchers have examined the degree to which computers may be used to facilitate creativity; however, the results are inconclusive (Edwards, 2001: 223). In this section we argue that if used effectively, technologies, especially computers, can provide a learning atmosphere that can facilitate creativity in learners.

A major force that seems to facilitate the emergence of creative personalities is the naturenurture relationship. As teachers we have very little or no control over the natural factors. However, a lot can be done in mathematics classrooms that can nurture the creative potential of our learners. The good news is that studies have confirmed that creativity comes more from environmental than hereditary factors (Simonton, 2000, Edwards, 2001). The importance of the environment on an individual's ability to be creative stems from the inherent nature of a human being to explore his surroundings and try to make novel associations between things. If the environment is conducive for making such connections, then creative abilities will be facilitated, otherwise they will be hindered (Edwards, 2001: 222). It is our belief that technologies can help teachers to develop an environment that can facilitate creative behaviour in their learners.

One of the unique features of the computer as a teaching and learning tool is visualisation. Through visualisation problems can be looked at from a macro perspective, and it allows for conceptualisation of the problem as a whole. It has been argued by Edwards (2001: 221) that eminent creativity comes from the ability to think visually instead of verbally. This has been demonstrated by examining many of the great minds of the world, and "several of these historical figures had great powers of visualisation and thus, the importance of nonverbal thought was recognised as an important component of creativity"(Edwards, 2001: 221). Dreyfus (1993) observes that during the last 30 years, mathematics as an activity has become more experimental and more visual. In line with this development, the computer is a unique tool that has the potential to enhance both the visual and the experimental features. For instance, the powerful visualisation capacity of the computer is unprecedented and incomparable with traditional teaching aids. Abstract concepts that have proved difficult for teachers to explain or for learners to grasp using traditional teaching approaches or aids can now easily be produced and understood by 
using the powerful animation and graphical display capabilities of computers. With this, learners' reasoning and manipulative powers are facilitated especially by computer graphics. Learners can also work with visualisation and modelling software to simulate concepts or ideas that are similar to real life situations. Not only will this increase the experimentation, exploration and understanding of the learners, but it also increases the likelihood of transferability of knowledge from school to real life settings (Dreyfus, 1993; Brandsford, Brown \& Cocking, 1999), therefore making mathematics sensible to learners. In a study on the influence of visualisation, exploring patterns and drawing generalisations, Nixon (2003) reported that her learners indicated visual representation in a computer screen as beneficial to their understanding compared to diagrams in books.

It is well known that the more senses we engage in the teaching and learning process the more we understand and retain knowledge. Through multimedia, educational technology has the capability of appealing to our senses of sight, hearing, and touch. So it has the ability to widen and enrich the content and scope of our educational experiences. Technology provides greater flexibility and variety in the organisation of instruction, and gives learners a more self-reliant role in their own education. This allows learners to become more active agents in managing and ensuring the success of their education - invariably sustaining their attention and commitment to mathematics.

Technology can assist teachers in developing a creative learning situation that takes cognisance of individual learning differences. Also, it empowers learners and avails them of all the tools necessary for promoting creativity. There is no doubt that one of the greatest assets a teacher can possess is access to and technical know-how of technology because of its versatility. For instance, the preparation of teaching material for presentation in the classroom takes up most of teachers' time. With the help of technology, the teacher can effectively address the challenge to organise mathematics instruction so that it attracts and develops the abilities of the greatest number of learners possible (NCTM, 2000). Multimedia, for example, merge text, graphics, audio, and video into one entity, and hence makes it possible for learners to use many of their senses in one lesson (see Hale, 2004). This brings about the possibility of accommodating many learners with different learning styles in an unprecedented way - hence making learning mathematics more meaningful.
Furthermore, it is common knowledge that people use and follow different ways of collecting and organising information into useful knowledge. Some accomplish their best learning through interaction with their peers. Others accomplish this through lone study and contemplation. Certain individuals on the other hand prefer to learn a skill by manipulating concrete objects, watching, listening, or by reading an instruction manual (Cross, 1976). Issues such as time constraints, the teachers' experience and so on, make it extremely difficult for the teacher to cater for these individual differences. This situation sometimes results in learning difficulties for some learners. To address this, some teachers resort to more or less prescriptive teaching, where the rules and mechanics of teaching are followed, while others use creative teaching, which approaches situations in an unprecedented way. Now computers provide learners with access to instructional programs designed with bigger budgets, more expertise, and greater talent than would be possible in the realm of human teaching. This enriches and supplements the classroom instruction that is already available to learners, hence providing them with alternative modes of instruction for the same subject. Furthermore, this increases independent learning which is good for creativity.

Paul and Kathy (1990) define creative learning as a natural healthy human process that occurs when people are curious and excited. Good learning on the other hand requires learners to follow skills such as recognition, memory and logical reasoning, which are the abilities frequently assessed in tests of intelligence and scholastic aptitude (Paul \& Kathy, 1990). However, creative thinking and learning involve the abilities to sense problems, inconsistencies, and missing elements, fluency, flexibility, originality, and elaboration and redefinition (Paul \& Kathy, 1990). It has been shown that learners prefer to learn in creative ways rather than by just memorising information provided by a teacher or parents and that they also learn better and sometimes faster when a creative approach is used (Paul \& Kathy, 1990; Simonton, 2000). However, these are abilities that are rarely developed in our classrooms despite "good" teaching intentions. To promote these, mathematics should be viewed differently - as a science of pattern rather than as a set of rules. In this regard learners should be given more control over what they learn in order for them to explore and appreciate these patterns. They should be actively involved in the learning process and the pattern searching for knowledge to be meaningful. 
In a typical classroom, technology saves time and provides easier and clearer illustrations than those a teacher would make. As a matter of fact, there are relatively very few teachers that have the time or artistic talent to produce illustrations "by hand with chalk, overhead transparency pens, or marking pens that can compete with those generated with a computer" (Cangelosi, 1996: 202), or even graphic calculator. This can be seen in the case of three-dimensional objects. Such objects are difficult to draw on the chalkboard and it is much more difficult for learners to visualise them. With the help of computers and graphic calculators learners themselves may creatively draw three dimensional objects, thus saving teachers' precious and limited time. It has been shown that working with the appropriate computer software can pack a large amount of graphing experience into a relatively short amount of time with the result that learners deal with more graphs in class than learners typically experience in an entire series of algebra courses (see Kaput, 1992; Yushau, 2004), therefore, leaving them with more time and opportunity for creative work.

Motivation is considered to be a driving force for most human endeavours. In fact motivation has been a major research topic in the area of the psychology of teaching and learning (Perry, Menec \& Struthers, 1996). Bell (1978) outlines four general reasons for people to be motivated to learn in and outside of school. These are: "to create things, to make things work, to obtain recognition, and to find personal satisfaction" (1978: 33). If learners are to be motivated and their enthusiasm enhanced, it is important that instruction be flexible enough to create room for creativity to prosper. Technology has the potential of making this a possibility and as a consequence it develops the high level of motivation necessary for creativity. For instance, the intrinsic features of computers such as immediate feedback, animation, sounds, interactivity, and individualisation are more likely to motivate learners to learn than any other media (Yang \& Chin, 1996). The spontaneous attention of children watching good movies, cartoons or doing computer games is apparent. It has been shown that if these technologies are properly used teachers can motivate learners to learn extrinsically and intrinsically (Cox, 1997), which are both necessary for creativity.

On the side of the learner, the creative potential seems to require certain exposure to diversifying experiences that help weaken the constraints imposed by conventional socialisation and challenging experiences that help strengthen a person's capacity to persevere in the face of obstacles (Simonton, 2000: 153). There is no doubt that using a variety of technological tools, such as calculators, computers, and hands-on materials, under the guidance of a skilful teacher, creates a rich mathematical learning environment. Such an environment helps in exposing and preparing learners for diversified experiences experimentation and exploration (Beal, 1998). This is the exposure that is required and necessary to nurture creativity (De Villiers, 2004; Nixon, 2003).

One of the factors that limit learner creativity in mathematics is their inability to recognise and connect mathematical structures and objects in different situations. In this respect, technology can help learners uncover shared and unshared patterns of a class of mathematical objects. For instance, the multiple representation for a function (tabular, graphical, symbolic), is much easier to grasp using technology. It has been demonstrated by Yushau (2004) how one can display all these representations of one-dimensional functions in one setting in MatCAD. In that setting learners need only change a parameter to see changes in all these aspects. This in a way exposes learners to different sides of the 'mathematical coin' and allows them to see mathematics from different (and seemingly unrelated) angles. Such exposure helps them to visualise, explore and deeply understand mathematical concepts in a spectacular way (Cangelosi, 1996), invariably fostering their mathematical creativity. It is this exposure that informs learners that mathematics is not a linear subject and that there are a variety of ways of tackling problems. It also removes pervasive beliefs that the only way of tackling mathematics is by following rules, which in fact kills creativity.

Learning is an active process. However, many commonly used teaching strategies put learners in passive and receptive roles. This results in situations where learners have very little, if any, control of the learning environment (Bell, 1978). Technology has the ability to enrich the content of learners' learning experiences, provide greater flexibility and give learners a more self-reliant role in their own education. As a result, learners become more active and participating agents in their education, which will open the door for creativity.

Creativity is more or less a solitary business (Standler, 1998). Similarly, learning is more effective and efficient when instruction can be tailored to the unique needs of each learner. With the aid of technology, especially computers, 
instruction can be flexible and adaptable to individual needs. Also learner-teacher interaction and learning are significantly more learner-centred, thereby, creating room for learners' optimal functionality and creativity.

Today's learners will live and work in the twenty-first century, in an era dominated by computers, by worldwide communication, and by a global economy. Jobs that contribute to this economy will require workers who are prepared to absorb new ideas, to perceive patterns, and to solve unconventional problems (Steen, 1989). Under this dispensation, there is no better gift that a learner can get from school than empowering him/her with the necessary tools to face this challenge. It has been established that use of technology can empower learners to be critical thinkers, and better problem solvers (Kaput, 1992; Roblyer, 1989). In this way, their creative capabilities may be enhanced.

Thinking mathematically is considered (by many people) to be critical for everyday life skills. People use mathematical skills daily to identify problems, look for information that will help them solve problems, consider a variety of solutions, and communicate the best solution to others. However, the connection between the mathematics learned at school and the mathematics used in daily life is often not made. To bridge this gap, mathematics classrooms should provide practical experiences in mathematical skills that are a bridge to the real world. Also, they should allow explorations that can develop an appreciation of the beauty and value of mathematics (Beal, 1998). Again the use of technology is a key for bridging this gap. This may be accomplished by providing learners with a variety of challenging real life problems that are fascinating, interesting, exciting, thrilling, important, and thought provoking - a wonderful asset for fostering creativity (see Papert, 1980). This will help the learners to visualise and appreciate mathematical concepts and to look for creative solutions to real-world problems.

Although computers, as argued, have the potential to foster the creativity of learners in many different ways, three points are summarised by Edwards (2001: 226) as necessary for accomplishing this. First, computer programs should allow for the destructuring of thought to facilitate the building of new creative concepts based on old patterns of thinking. Second, the idea that a computer can aid in that process provides evidence that the highly structured environment of the computer can be used to facilitate creativity and not just to limit it. Last, the idea of allowing people to determine the time spent considering options, and the general focus of control being with the individual, seems to be especially important to the facilitation of creativity.

\section{Conclusion}

The main focus of this paper is on technology in general and the computer in particular. In the course of this review, we have seen that technology is a powerful tool that could be used in the teaching and learning context to make a difference to our traditional teaching methods. It has the capacity to "amplify" and "organise" our thought, teaching and learning process (Pea, 1987). If used effectively computers are a proven medium for fostering creativity and divergent thinking in the classroom (Edwards, 2001). They have the potential to provide a teacher with an enabling situation to create a rich and challenging learning environment that can foster the creative potential of learners. On the other hand, computers can give learners the opportunity to explore their own creative potential. Therefore,

The question of whether a child can learn and do more mathematics with a computer ... versus traditional media is moot, not worth proving. That computational aids overall do a better job of converting a child's intellectual power to mathematical achievement than do traditional static media is unquestionable. The real questions needing investigation concern the circumstances where each is appropriate. (Kaput, 1992: 518)

While the mathematics teachers search for the best time and circumstances to use technology to foster the mathematical creativity of their learners,

many scenarios could be envisioned concerning the use of computers and technology in the future, I would like to believe that the future is what we make of it. (Edwards, 2001: 227)

\section{Acknowledgements}

The first author acknowledges with thanks the help of the research facility at KFUPM during the preparation of this paper.

\section{References}

Beal, R.W. (1998). The "Write" way to do mathematics. Retrieved February 12, 2002, from http://www.elm.maine.edu/assessments/2_ math/INDEX.STM. 
Bell, F.H. (1978). Teaching and learning mathematics: In secondary schools. Dubuque, Iowa: W. C Brown.

Brandsford, J., Brown, A. \& Cocking, R. (Eds.) (1999). How people learn: Brain, mind, experience and school. Washington DC: National Academy Press. Online version available at http://books.nap.edu/html/how people1/

Cangelosi, J.S. (1996). Teaching mathematics in secondary and middle school: an interactive approach (2nd Edition). New Jersey: Prentice Hall.

Carnegie Commission on Higher Education (1972). The Fourth Revolution: Instructional technology in higher education. New York: McGraw-Hill.

Chambers, J.A. (1972). College teachers: Their effect on creativity of students. Final Report, University of South Florida, Tampa.

Corcoran, K. (2000, November 28). Teachers strive to show what adding technology to classrooms can mean. San Jose: Mercury News. Retrieved September 15, 2001, from http://www.siliconvalley.com/mld/siliconvalley /news/local/

Cox, M.J. (1997). The Effects of Information Technology on students' motivation. Final Report. NCET/King's College London.

Cross, P.K. (1976). Improving instruction and reshaping the curriculum. San Francisco: Jossey-Bass, Inc.

De Villiers, M. (2003). The value of experimentation in Mathematics. In 9th Congress Proceedings of AMESA, Vol. 1 (pp. 174-185).

De Villiers, M. (2004). The value of experimentation in Mathematics. In 10th Congress Proceedings of AMESA, Vol. 1 (pp. 93-104).

De Villiers, M. (2004). The role and function of Quasi-empirical Methods in Mathematics. Canadian Journal of Science, Mathematics and Technology Education, 4(3). 397-418.

Dreyfus, T. (1993). Didactic Design of Computerbased Learning Environments. In C. Keitel \& K. Ruthven (Eds.). Learning from Computers: Mathematics Education and Technology (pp 101-130). Berlin: Springer-Verlag.

Dunham, P.H. \& Dick, T.P. (1994). Research on graphing calculators. Mathematics Teacher, 87, 440-445.

Edwards, S.M. (2001). The Technology Paradox: Efficiency Versus Creativity. Creativity Research Journal, 13(2), 221-228.
Freudenthal, H. (1973). Mathematics as an Educational Task. Dordrecht: Kluwer Academic Publishers.

Hale, M.E. (2004). Use of multimedia in mathematics education. The Mathematics Educator, 4(1), 1-2.

Heimer, R.T. (1972). A Critical analysis of the use of educational technology in mathematics teaching, in New Trends in Mathematics Teaching, UNESCO. Paris: UNESCO.

Jacob, B.L. (1996). Algorithmic composition as a model of creativity. Retrieved June 12, 2001, from http://citeseer.nj.nec.com/jacob96algorith mic.html

Kadiyala, M. \& Crynes, B. (1998). Where is the proof? A review of literature on effectiveness of information technology in education. Retrieved July 25, 2002, from http://fie.engrng.pitt.edu/ fie98/authors/K.htm

Kaput, J.J. (1992). Technology and mathematics education, in D. A. Grouws (Ed.) Handbook for research in mathematics education (pp 515556). New York: McMillan.

Krska, J. (2001). Use of technology in the classroom - Science focus. Retrieved March 16, 2002, from http://scied.unl.edu/pages/ courses/800summaries/krska.html

Meissner, H. (2000). Creativity in mathematics education. Yokochi 3 Vortrag Tokyou. Retrieved August 9, 2001, from http://www. mcrel.org/products/csmp/frederique/asp

Murray, H, Olivier, A. \& Human, P. (1992). The development of young students' division strategies. Proceedings of the Sixteenth International Conference for the Psychology of Mathematics Education, Vol. 2 (pp. 152-159). Durham, New Hampshire.

Nakin, J.B.N. (2003). Creativity and divergent thinking in geometry teaching and learning. Unpublished D.Ed thesis (in progress), University of South Africa, Pretoria.

National Council of Teachers of Mathematics (NCTM) (2000). Principles and Standards for School Mathematics. Reston, VA: National Council of Teachers of Mathematics.

Nixon, E.G. (2003). An investigation of the influence of visualisation, pattern formation and generalisation on thinking levels in the formation of the concepts of sequences and series. Unpublished MEd dissertation, University of South Africa, Pretoria.

Noddings, N. (1994). Does everybody count? Reflections on reforms in school mathematics. Journal of Mathematical Behavior, 13(1), 89104. 
Papert, S. (1980). Mindstorm: Children, computers, and powerful ideas. Sussex: The Harvester Press Limited.

Papert, S. (1990). A critique of technocentrism in thinking about the school of the future (M.I.T. Media Lab Epistemology and Learning Memo No. 2). Retrieved March 21, 2001 from http://www.papert.com/articles/ACritiqueofTec hnocentrism.html

Paul, E.T. \& Kathy, P.G. (1990). Fostering academic creativity in gifted students. ED321489 1990, ERIC EC Digest \#E484. Retrieved November 23, 2001, from http://ericae.net/edo/ED321489/484

Pea, R.D. (1987). Cognitive technologies for mathematics education. In A.H. Schoenfeld (Ed.), Cognitive science and mathematics education (pp 89-122). Hillsdale, NJ: Erlbaum.

Perry, R.P., Menec, V.H. \& Struthers, C.W., (1996). Student motivation from the teacher's perspective. In R. Menges \& M. Weimer (Eds.), Teaching on Solid Ground: Using Scholarship to Improve Practice (pp 75- 100). San Francisco: Jossey-Bass.

Polya, G. (1957). How to solve it. New Jersey: Princeton University Press.

Quigley, P. (1998). Creativity and computers. Retrieved February 22, 2002, from http://arts. anu.edu.au/philosophy/confweb/Quigley.htm

Ripple, R. E. (1989). Ordinary creativity. Contemporary Educational Psychology, 14, 189-202.

Roblyer, M.D. (1989). The impact of microcomputer-based instruction on teaching and learning: A review of recent research. ERIC Digest. Retrieved December 10, 2001, from http://ericae.net/edo/ED315063.htm

Schmalz, R. (1988). The role of intuition in doing mathematics. Journal of Mathematical Behaviour, 7, 33-44.
Setzer, V.W.A. (2001). Review of arguments for the use of computers in elementary education. Retrieved September 19, 2001, from http://www.ime.usp.br/ vwsetzer

Simonton, K. (2000). Creativity. American Psychologist, 55(1), 151-158.

Sriraman, B. (2004). The Characteristics of Mathematical Creativity. The Mathematics Educator, 14(1), 19-34

Standler, R.B. (1998). Creativity in science and engineering. Retrieved January 13, 2002, from http://www.rbs0.com/create.htm

Steen, L.A. (1989). Teaching mathematics for tomorrow's world. Educational Leadership, 47(1), 18-22.

Westby, E.L. \& Dawson, V.L. (1995). Creativity: Asset or burden in the classroom? Creativity Research Journal, 8, 1-10.

Yang, Y. \& Chin, W. (1996). Motivational analyses on the effects of type of instructional control on learning from computer-based instruction. Journal of Educational Technology System, 25(1), 25-35.

Yushau, B. (2004). Using MathCAD to teach onedimensional graphs. International Journal of Mathematical Education in Science and Technology, 35(4), 523-529.

Yushau, B, Mji, A, Wessels, D.C.J. \& Bokhari, M.A. (2005). Predictors of success in Computer Aided Learning of Mathematics. In G. M. Lloyd, M. R. Wilson, J. L. Wilkins, \& S. L. Behm (Eds.), Proceedings of the $27^{\text {th }}$ annual meeting of the North American Chapter of the International Group for the Psychology of Mathematics Education [CD-ROM]. Eugene, OR: All Academic.

"If you are seeking creative ideas, go out walking. Angels whisper to a man when he goes for a walk."

Raymond Inmon 